\title{
Costa Rica, de la educación especial a la educación inclusiva. Una mirada histórica
}

\author{
Costa Rica, from special education to inclusive education. A historical \\ perspective
}

Costa Rica, da educação especial à educação inclusiva. Uma abordagem histórica

\author{
María del Rocío Deliyore Vega ${ }^{1}$ \\ Universidad de Costa Rica, Costa Rica
}

Recepción: 19/11/2017

Evaluación: 24/11/2017

Aceptación: 29/06/2018

Artículo de Revisión

DOI: $10.19053 / 01227238.8600$

\section{RESUMEN}

La educación especial en América Latina se encuentra en un momento de constante transformación, cuyos cambios se han suscitado debido a la evolución en el concepto de discapacidad y al surgimiento del nuevo paradigma de educación inclusiva. El presente artículo tiene como objetivo realizar un recuento de dicha transformación, centrando su atención en los cambios costarricenses de la disciplina y analizando los desafíos que aún prevalecen. Para ello, se realiza una investigación histórica de revisión documental centrada en la contrastación y la validación de fuentes. Tras analizar la evolución conceptual de la discapacidad y la educación especial en Costa Rica y América Latina, se concluye que prevalecen servicios segregacionistas a la vez que emergen servicios de educación inclusiva, haciendo necesario un análisis epistemológico de la educación especial en Costa Rica que determine las nuevas miradas de la disciplina e impulse cambios contundentes en virtud de defender los derechos humanos de las personas en condición de discapacidad.

Palabras clave: Revista Historia de la Educación Latinoamericana; educación especial; discapacidad; integración escolar; igualdad de oportunidades.

1 Doctora en Educación Docente e investigadora en la Sección de Educación Especial de la Universidad de Costa Rica y el Instituto de Investigaciones en Educación, líneas de investigación: Educación inclusiva y comunicación alternativa y aumentativa. Correo electrónico: maria.deliyorevega@ucr.ac.cr 


\begin{abstract}
Special education in Latin America is at a time of constant transformation due to the evolution of the concept of disability and the emergence of the new paradigm of inclusive education. The objective of this article is to recapitulate this transformation. We focus on the Costa Rican changes in this discipline and analyze the challenges that still prevail. For this, a historical documentary research centered on the verification and validation of sources was carried out. After analyzing the conceptual evolution of disability and special education in Costa Rica and Latin America, it is concluded that segregationist services prevail while inclusive education services emerge. This implies the need for an epistemological analysis of special education in Costa Rica that shapes the new perspectives of the discipline and promotes forceful changes in order to protect the human rights of people with disabilities.
\end{abstract}

Keywords: Journal History of Latin American Education; special education; disability; school integration; equal opportunities.

\section{RESUMO}

A educação especial na América Latina se encontra em um momento de cons- tante transformação, cujas mudanças ocorreram devido à evolução do conceito de deficiência e ao surgimento do novo paradigma de educação inclusiva. O presente artigo tem como objetivo contar a referida transformação, centrando sua atenção nas mudanças costarriquenses da disciplina e analisando os desafios que ainda prevalecem. Para isso, foi feita uma pesquisa histórica de revisão documental centrada no contraste e na validação de fontes. Depois de analisar a evolução conceitual da deficiência e da educação especial na Costa Rica e na América Latina, conclui que prevalecem serviços segregacionistas ao invés de emergirem serviços de educação inclusiva, sendo necessária uma análise epistemológica da educação especial na Costa Rica que determine as novas abordagens da disciplina e impulsione transformações contundentes em virtude de defender os direitos humanos das pessoas com deficiência.

Palavras-chave: Revista História da Educação Latino-americana; educação especial; deficiência; integração escolar; igualdade de oportunidades.

\section{INTRODUCCIÓN}

En Costa Rica, la educación especial se ha definido de modo legislativo por medio del artículo 27 de la Ley 7600, en la que se indica que "La educación especial es el conjunto de apoyos y servicios a disposición de los alumnos con necesidades educativas especiales, ya sea que los requieran temporal o permanentemente $^{2 \prime}$. No obstante, a la luz de los cambios filosófico-políticos de la educación inclusiva, se ha cuestionado la epistemología de la educación especial, como se organiza actualmente. En este sentido se discute que la educación especial, tal como se dispone, mantienen funcionando entornos educativos segregantes que no respetan el compromiso con la inclusión social del estudiantado, así mismo en su nombre contiene palabras como "especial" y etiquetas como "necesidades educativas especiales", marcando una clara distinción entre grupos humanos que se aleja del respeto a la diversidad y el enfoque positivo sobre las condiciones que nos distinguen como sociedad.

2 Asamblea Legislativa, "Ley 7600. Igualdad de oportunidades para las personas con discapacidad” (San José: Ministerio de Justicia, 1996). 
Al respecto, la investigadora Lady Meléndez hace un estudio de la evolución de la educación especial en Costa Rica, donde explica que:

Cuando los movimientos integracionistas de los años 70 y 80, opuestos decididamente a la segregación que caracterizaba a las escuelas residenciales, iniciaron la promoción del derecho que tiene toda persona con discapacidad de ser educado en el ambiente menos restrictivo posible y en el lugar más cercano a su casa, impulsaron también el cambio drástico en la organización de los servicios educativos33.

De ahí en adelante, según la autora, se desprendieron una serie de investigaciones que afirmaron que la mejor oferta educativa para la población en condición de discapacidad era la que se recibiera en la escuela de su comunidad, favoreciendo así su mayor participación social y un acercamiento más profuso a la igualdad de oportunidades. En este sentido, "las escuelas segregadas, sobre todo las que obligaban a la institucionalización residencial, no podían competir nunca con los niveles de motivación que ofrecían las nuevas ofertas educativas $^{\prime 4}$. Tales cambios políticos generaron grandes expectativas de cambio en la población costarricense. Aunado a ello, la Convención sobre los Derechos de las Personas con Discapacidad, a la que se adscribe Costa Rica, indica en su artículo 24 que:

Los Estados Partes reconocen el derecho de las personas con discapacidad a la educación. Con miras a hacer efectivo este derecho sin discriminación y sobre la base de la igualdad de oportunidades, los Estados Partes asegurarán un sistema de educación inclusivo a todos los niveles, así como la enseñanza a lo largo de la vida (... $)^{5}$.

No obstante, la educación especial en Costa Rica cuenta aún con entornos segregantes, de larga estancia para la mayoría de sus usuarios y evoluciona a un cambio lento hacia la postura inclusiva. Así también se plantea en el Informe del estado de la niñez y la adolescencia con discapacidad en Costa Rica, cuando afirma que:

Las políticas y planes del MEP aún no han logrado incorporar plenamente la discapacidad desde un enfoque inclusivo, se mantienen una serie de barreras y resistencias que se traducen en mala calidad de educación, deficiencias en la aplicación de las adecuaciones curriculares, barreras culturales y actitudinales, en particular, de los y las docentes que no reciben una formación profesional enfocada en la educación inclusiva ${ }^{6}$.

3 Lady Meléndez, La educación especial en Costa Rica. Fundamentos y evolución (San José: Editorial Universidad Estatal a Distancia, 2010), 98.

4 Ibíd.

5 Naciones Unidas, Convención sobre los "Derechos de las Personas con Discapacidad y Protocolo Facultativo" (New York: Naciones Unidas, 2006), acceso el 15 de mayo de 2015, http://www.un.org/disabilities/documents/convention/convoptprot-s.pdf.

6 Paula Antezana, Una aproximación a la situación de la niñez y la adolescencia con discapacidad en Costa Rica (San José: Segunda Vicepresidencia de la República, CNREE y Unicef, 2014), 11-12. 
Ahora bien, esta dificultad de transformación de igual forma ha generado cambios fuera de las fronteras nacionales. En otros contextos los cambios han llevado a considerar la importancia del trabajo cooperativo en las acciones pedagógicas que se construyan con el estudiantado con discapacidad. Gallego y Rodríguez, en España por ejemplo, definen la disciplina de la educación especial desde las dimensiones teórico-conceptual y práctica. En este sentido, los autores explican que dichas dimensiones

(...) no son propiedad exclusiva del pedagogo, logopeda, psicólogo, trabajador social o médico, por citar sólo a algunos de los profesionales implicados, sino del conjunto de profesionales que reconocen y asumen una actuación inter e intradisciplinar como la opción más acertada para acercarse a la realidad que se pretende ayudar.

La colaboración propuesta por los autores supone que la educación especial amerita un esfuerzo conjunto en virtud de una educación de calidad para todas las personas implicadas. Se asume, entonces, la educación especial, como una herramienta de cambio, que genere espacios inclusivos y que empodere a las poblaciones vulnerables.

La educación especial, por tanto, representa una participación social de transformación hacia la mejora de la calidad de vida de las personas en condición de discapacidad. Actualmente, sus acciones trascienden las barreras del aula y promueven la inclusión social en todos los contextos en los que se desenvuelva el colectivo. Gallego y Rodríguez afirman, en este marco, que: “También es una forma de luchar contra la exclusión, contra la negación de los derechos individuales o la omisión de deberes sociales, que se produciría cuando los sistemas sociales, económicos y culturales que determinan la integración de las personas en la sociedad no atendieran por igual a todos los ciudadanos" ${ }^{8}$.

En esta línea, el equipo profesional que labore con la población escolarizada en condición de discapacidad, se encuentra en el seno de una responsabilidad mayor, en la que sus acciones deben encaminarse a promover los derechos de igualdad y autonomía del estudiantado. Para ello, es indispensable hacerlo en los entornos menos restrictivos posibles. No puede hablarse de una participación inclusiva en un contexto segregado, por tanto, para cumplir con el deber social que supone la educación especial, no debe obviarse que "la inclusión social sería la manera de hacer valer los derechos de las personas, otorgándoles voz y voto, haciéndoles participar e integrarse en los diferentes sistemas" ${ }^{\prime \prime}$.

Así las cosas, Costa Rica está en un momento histórico de transformación en lo que compete al análisis epistemológico de la educación especial y que, pese a que cuenta con una definición legislativa que regula la profesión, la disciplina

\footnotetext{
7 José Luis Gallego y Antonio Rodríguez, Bases teóricas y de investigación en educación especial (Madrid: Ediciones Pirámide, 2012), 18-19.

8 Ibíd., 15

9 Ibíd., 20.
} 
misma está en constante evolución por lo que requiere un replanteamiento, tanto de sus funciones como de su enfoque social.

\section{Aproximación histórica del concepto de discapacidad}

El concepto de discapacidad evoluciona constantemente y a su marcha transforma tanto los principios bajo los que se enmarca, como la perspectiva de la ciudadanía ante su presencia. A continuación, se realiza un breve recuento de cada modelo en que ha transcurrido su evolución, en aras de interpretar con mayor claridad su construcción actual.

Modelo de la prescindencia. Este modelo se distingue desde la época clásica hasta el Renacimiento y se caracteriza por la creencia de que la sociedad podía prescindir de la población en condición de discapacidad. Durante esta época, "las personas con discapacidad se consideran innecesarias porque no contribuyen a la comunidad, porque simbolizan un castigo divino"10. Bajo esa postura, las políticas públicas permitían las prácticas de sometimiento o tratos caritativos. Por otra parte, en este modelo también "Se asume que las causas que dan origen a la discapacidad son religiosas: un castigo de los dioses por un pecado cometido generalmente por los padres de la persona con discapacidad, o una advertencia de los dioses acerca de que la alianza se encuentra rota y que se avecina una catástrofe"11.

Estas posturas que otorgan a la población sin discapacidad un rol de superioridad, son empleadas para tomar acciones de control que originan dos submodelos: el eugenésico y el de la marginación. El primero permitía el infanticidio. Por tanto "la costumbre de eliminar a niños y niñas con discapacidad no solo se sustentaba en motivos religiosos, sino también prácticos, pues era económicamente pesado e improductivo criar hijos e hijas con discapacidad" ${ }^{12}$. Por otro lado, los niños y niñas que lograban eludir el infanticidio "eran destinados a vivir en condiciones extremas de rechazo"13.

El submodelo de la marginación se caracteriza por excluir a la población en condición de discapacidad, sin cometer el infanticidio de modo directo. Este modelo excluye por "subestimar a las personas con discapacidad y considerarlas objeto de compasión, o como consecuencia del temor o el rechazo por considerarlas objeto de maleficios o la advertencia de un peligro inminente" ${ }^{\prime 14}$. Los niños y niñas recurrían a la mendicidad o vivían resignados a la esclavitud. Finalmente, en esta postura la percepción social implica un alto nivel de menosprecio hacia la población en condición de discapacidad que generaba lástima, rechazo $\mathrm{y}$ violencia sin regulación alguna.

10 Antezana, op. cit., 23.

11 Agustina Palacios, El modelo social de discapacidad: orígenes, caracterización y plasmación en la Convención Internacional sobre los Derechos de las Personas con Discapacidad (Madrid: CERMI/Ediciones Cinca, 2008), 37.

12 Antezana, op. cit., 24.

13 Ibíd.

14 Palacios, op. cit., 54. 
Modelo rehabilitador. A inicios del siglo xx surge el modelo rehabilitador, impulsado por la cantidad de personas con lesiones debidas a la Primera Guerra Mundial. El objetivo era reincorporar a este grupo tan significativo de población al mercado laboral. Las causas de su origen, por tanto, fueron científicas. Paula Antezana explica que "el fin último de este modelo es normalizar a las personas con discapacidad"15, es decir, esconder su deficiencia, de modo que tengan un comportamiento lo más parecido posible a la norma. Palacios explica que, desde esta visión:

Se considera que la persona con discapacidad puede resultar de algún modo rentable a la sociedad, pero dicha rentabilidad se encontrará supeditada a la rehabilitación o normalización y, esto significa, en definitiva, supeditarlo a que la persona logre asimilarse a los demás - válidos y capaces - en la mayor medida de lo posible ${ }^{16}$.

Ahora bien, la evolución de un modelo a otro trajo grandes avances hacia la percepción de la población en condición de discapacidad y su participación social. Impera ahora un modelo biomédico que "asume que existe una relación lineal entre la etiología, la patología y las manifestaciones de las deficiencias"17. A pesar de que tal postura ignora aún los aspectos familiares y emocionales de la persona, este nuevo enfoque da una mayor atención al concepto ecológico de la discapacidad, "es decir al criterio de multicausalidad que revaloriza la importancia del papel del medio"18. Al explicar la discapacidad desde causas médico-científicas, se empiezan a buscar medios para mejorar la calidad de vida de dichas personas.

Palacios afirma al respecto, que "en este modelo se busca la recuperación de la persona - dentro de la medida de lo posible-, y la educación especial se convierte en una herramienta ineludible en dicho camino de recuperación o rehabilitación"19. La integración de la persona con discapacidad constituye una meta social para la cual "se establecieron servicios hospitalarios, de educación y ocupacionales; estos últimos funcionaban como talleres protegidos" 20 , todo ello en busca de mayor productividad e independencia. No obstante Amate y Vásquez afirman que en el marco del paradigma biomédico que impera en este modelo, "los recursos se volcaron a los servicios y no a la satisfacción de las verdaderas necesidades de las personas con limitaciones funcionales"21. Por tanto, su participación estaba siempre sujeta a la capacidad que tuviesen de adaptarse al contexto, otorgando total responsabilidad de su integración a las personas con discapacidad y no a otros miembros del colectivo.

15 Antezana, op. cit.

16 Palacios, op. cit., 66-67.

17 Alicia Amate y Armando Vásquez, eds., Discapacidad: lo que todos debemos saber (Washington, D. C: Organización Panamericana de la Salud, 2006), 5.

18 Ibíd., 3.

19 Palacios, op. cit.

20 Amate y Vásquez, op. cit., 7.

21 Ibíd. 
Modelo social. "Nada de nosotros sin nosotros"22. Sirva la anterior cita para introducir el modelo social, que surge en los años noventa y persiste hasta la actualidad. El mismo fue impulsado por causas de índole social, en las que se reconocía que las personas en condición de discapacidad pueden y deben aportar positivamente a la sociedad del mismo modo que cualquier otra persona. Este nuevo enfoque, tal como lo indica la cita introductoria, nace a causa de las luchas que emprenden las personas en condición de discapacidad por hacer valer sus derechos humanos.

Se logra entonces que la Convención sobre los Derechos de las Personas con Discapacidad asuma como una consideración que "las personas con discapacidad deben tener la oportunidad de participar activamente en los procesos de adopción de decisiones sobre políticas y programas, incluidos los que les afectan directamente" ${ }^{23}$. En este sentido, las personas con discapacidad adquieren voz y logran empoderarse sobre sus posturas en las decisiones políticas que les competen.

Dicho modelo defiende que: "No son las limitaciones individuales las raíces del problema, sino las limitaciones de la propia sociedad, para prestar servicios apropiados y para asegurar adecuadamente que las necesidades de las personas con discapacidad sean tenidas en cuenta dentro de la organización social"24. El enfoque social parte de valorar y dignificar las capacidades de cada persona con igualdad de condiciones. Al hacerlo, reconoce que la sociedad tiene la responsabilidad de aceptar, respetar y asegurar el acceso de las personas con discapacidad en su contexto. En este sentido, la Convención sobre los Derechos de las Personas con Discapacidad reconoce que "La discapacidad es un concepto que evoluciona y que resulta de la interacción entre las personas con deficiencias y las barreras debidas a la actitud y al entorno que evitan su participación plena y efectiva en la sociedad, en igualdad de condiciones con las demás" ${ }^{\prime 25}$.

Para que la interacción propuesta por la Convención sea oportuna, es indispensable que se desarrolle una cultura inclusiva y respetuosa de la diversidad en todos los contextos sociales. Agustina Palacios al respecto señala que, pese a que se reconoce el valor tan importante de los aportes de las personas con discapacidad, "su contribución se encuentra supeditada y asimismo muy relacionada con la inclusión y la aceptación de la diferencia" ${ }^{26}$. Agrega la autora que en esta línea la visión debe enmarcarse en "rescatar las capacidades en vez de acentuar las discapacidades" 27 .

Finalmente, el modelo social se centra en producir cambios sociales más que individuales, donde se reconozcan estas capacidades y en torno a ellas se diseñen las ciudades de modo universal.

\footnotetext{
22 Palacios, op. cit., 103.

23 Naciones Unidas, op. cit.

24 Palacios, op. cit., 103-104.

25 Naciones Unidas, op. cit.

26 Palacios, op. cit., 104.

27 Ibíd., 105.
} 
Los derechos humanos asumen un rol vital en el modelo social. Al respecto la Unicef, en el Estado mundial de la infancia. Niñas y niños con discapacidad, afirma que "adoptar un enfoque basado en el respeto a los derechos, las aspiraciones y el potencial de todos los niños y niñas puede reducir la vulnerabilidad a la discriminación, la exclusión y el abuso de los niños y niñas con discapacidad"28. Este enfoque demanda que las personas en condición de discapacidad asuman una participación plena, libre de barreras y con la libertad de decidir sobre su propia vida en igualdad de condiciones.

El marco sobre el que se estudia la discapacidad hoy en día ha sufrido cambios positivos gracias a la Clasificación Internacional del Funcionamiento de la Discapacidad y de la Salud (CIF). Este documento explica que "el funcionamiento de un individuo en un dominio específico se entiende como una relación compleja o interacción entre la condición de salud y los factores contextuales (ej. Factores ambientales y personales) ${ }^{\prime 29}$. Y se utiliza con el fin de realizar mediciones de clasificación frente a la discapacidad. En este sentido, la cif utiliza un enfoque biopsicosocial que se divide en cuatro componentes principales, a saber; las funciones corporales, incluyendo aquellas fisiológicas y psicológicas; la estructura corporal, considerando las partes anatómicas de la persona; las actividades de participación que pueda ejercer la persona en una tarea en particular y los factores ambientales, ya sean físicos, actitudinales o sociales que conducen la vida de la persona.

Esta nueva clasificación ha generado importantes reflexiones en torno a la conceptualización de la discapacidad. Su organización permite ampliar el panorama asistencialista construido en el marco de antiguos enfoques y trascender a una visión más inclusiva. La Unicef, en el Estado mundial de la infancia. Niñas y niños con discapacidad, reconoce que esta definición de la CIF, "normaliza de manera efectiva la discapacidad, al desviar la atención de la causa al efecto y admitir que todas las personas pueden sufrir algún tipo de discapacidad"30. En este sentido, puede decirse que es una conceptualización inclusiva con miras a mejorar la calidad de vida de todas las personas cuando se encuentran frente a una situación de discapacidad.

Costa Rica, por su parte; pese a que respeta las disposiciones de la oms y está adscrita también a la Convención sobre los Derechos de las Personas con Discapacidad, aún cuenta en su legislación con una definición reduccionista, que se centra únicamente en la persona, exonerando de responsabilidad al contexto. La misma se dispone en la "Ley 7600, Igualdad de oportunidades para las personas con discapacidad", donde indica que una discapacidad es "cualquier deficiencia física, mental o sensorial que limite, sustancialmente, una o más de las activida-

28 Unicef, Estado mundial de la infancia. Niñas y niños con discapacidad (Nueva York: Unicef, 2013), acceso el 4 de julio de 2016, http:// www.unicef.org/spanish/sowc2013/files/SPANISH_SOWC2013_Lo_res.pdf.

29 Organización Mundial de la Salud y Organización Panamericana de la Salud, Clasificación Internacional del Funcionamiento, de la Discapacidad y de la Salud (Madrid: Instituto de Mayores y Servicios Sociales (IMSERSO), 2001), acceso el 20 de julio de 2016, http:// apps.who.int/iris/bitstream/10665/43360/1/9241545445_spa.pdf.

30 Unicef, op. cit. 
des principales de un individuo" ${ }^{\prime 31}$. En este sentido es evidente la necesidad de una reforma nacional en la legislación, que contemple las posturas internacionales y se ajuste mejor al enfoque de derechos humanos.

\section{Breve recuento histórico de la educación especial en Latinoamérica}

La educación especial en América Latina se dirige a centralizar los actos educativos de la población en condición de discapacidad en contextos, inicialmente, separados de la escuela convencional. En este sentido, Enrique Gordillo señala que "una de las estrategias de la actividad educativa que se ha visto sometida a debate en los últimos tiempos, se relaciona con el agrupamiento escolar" ${ }^{\prime 32}$. Así mismo, la educación especial se ha transformado y repensado siempre a la luz de una organización estudiantil en miras de ser cada vez más justa y menos excluyente. Su evolución así lo denota, si bien los debates persisten y los cambios no siempre han asegurado el éxito en sus intenciones. A continuación, se describe brevemente la evolución de la educación especial a la luz de los modelos de la discapacidad, en los que versan los cambios de mirada sobre esta disciplina.

La educación especial, tal como se ha mencionado, tiene su origen en la era del modelo rehabilitador. En dicho momento pretendía ser una herramienta de normalización para la población en condición de discapacidad. Palacios afirma que "la educación especial entendida en los términos actuales podría situarse en los siglos XVIII y XIX, inicialmente para niñas y niños sordos y luego para aquellos con diversidades funcionales visuales" ${ }^{33}$. Explica la autora que "posteriormente se expandió exitosamente con las escuelas especiales pensadas para personas con discapacidades físicas e intelectuales. Así su implementación tuvo cabida a gran escala a principios del siglo $\mathrm{xx}$, como consecuencia de la responsabilidad asumida por los gobiernos" ${ }^{34}$.

La evolución del concepto de discapacidad, así como las diversas dinámicas sociopolíticas y las condiciones educativas de cada etapa histórica, generan cambios evolutivos en la educación especial que reformulan constantemente sus objetivos y funciones.

En Latinoamérica, la organización e institucionalización de la educación especial ha cursado varios momentos. Olga Díaz afirma que en sus inicios, durante el enfoque rehabilitador, se desarrolló "Un primer periodo, que se extendería desde los intentos por organizar instituciones especializadas a finales del siglo XIX hasta finales de la década de los 40 , en el que surgen las primeras escuelas de-

31 Asamblea Legislativa, "Ley 7600. Igualdad de oportunidades para las personas con discapacidad” (San José: Ministerio de Justicia, 1996).

32 Enrique Gordillo, "Historia de la educación mixta y su difusión en la educación formal occidental", Revista Historia de la Educación Latinoamericana, 17, n. ${ }^{\circ} 25$, (2015): 107-24. https://doi.org/10.19053/01227238.3814.

33 Palacios, op. cit., 84.

34 Ibíd. 
dicadas especialmente a la atención de niños sordos y ciegos, con un predominio de un servicio tipo médico-asistencialista" ${ }^{\prime 35}$.

En este periodo la educación especial se distinguió de la escuela ordinaria en tanto su población estudiantil se consideraba con algún tipo de deficiencia. Como resultado, explica Pilar Arnaiz, "el objeto de la educación especial segregada se centra en aquellas personas que por razones de orden fisiológico, psicológico o social necesitan ayudas o recursos especiales para adaptarse a las exigencias de su entorno y poder desarrollar sus posibilidades" ${ }^{36}$. En este sentido, el personal que laborara en los servicios de educación especial debía dominar técnicas y métodos diferentes a los empleados en la escuela ordinaria.

Durante esta época, la educación especial se caracteriza por trabajar la normalización de su población por medio de una postura educativa basada en igualar lo más posible la población con discapacidad a la población sin esta condición. Cabe destacar, entonces, dos principios elementales que surgen en este periodo y que dirigen las acciones gubernamentales nacionales e internacionales en materia de educación especial. El inicial es el de normalización, que: "Fue el primero en defender que las personas con retraso mental debían tener una existencia lo más parecida posible a la de los demás ciudadanos, desarrollar una vida tan normal como sea posible, puesto que una situación de vida segregada genera pocas oportunidades para integrase socialmente y para aprender como el resto de las personas" ${ }^{\prime 37}$.

$\mathrm{Al}$ tenor de estas apreciaciones, la protección de los derechos humanos defendió el derecho a la no marginación y generó nuevas expectativas en materia educativa para la población con discapacidad. Lo anterior en tanto que "el principio de normalización guarda relación con los medios más normalizadores posibles, con el fin de que las personas con deficiencias puedan mantener comportamientos y características personales lo más uniformes en el medio cultural en el que se desenvuelven"38. Es decir, reconoce la importancia de prestar servicios a la población con discapacidad de modo que aumentaran su posibilidad de ejercer una vida independiente.

De tal manera que en Latinoamérica, en los años cincuenta y sesenta, se dan grandes avances en materia de educación especial. La investigadora Díaz expone que:

\begin{abstract}
Aparecen los primeros centros de atención para niños con discapacidad; empiezan a presentarse servicios de capacitación laboral para adultos con limitación, especialmente para ciegos y limitados neuromusculares y ortopédicos; se crean programas profesionales orientados a brindar atención especializada a esta población, entre los que se destaca la terapia física, ocupacional y del lenguaje ${ }^{39}$.
\end{abstract}

\footnotetext{
35 Olga Díaz, "Conceptualización de la educación especial en Iberoamérica”, en La educación especial en Iberoamérica, eds. Olga Díaz, Sandra Rojas y Eloísa Vasco (Madrid: Organización de Estados Iberoamericanos (OEI), 2000), 15.

36 Pilar Arnaiz, Educación inclusiva: una escuela para todos (Málaga: Ediciones Aljibe, S. L., 2003), 11.

37 Pilar Arnaiz, Atención a la diversidad. Programación curricular (San José: Editorial Universidad Estatal a Distancia, 2013 ), 14.

38 Ibíd., 12.

39 Olga Díaz, op. cit., 16.
} 
En este periodo se expande la atención en todo el ámbito iberoamericano, alcanzando a disminuir el número de familias que acostumbraban a ocultar a sus miembros en condición de discapacidad. Así mismo se inició la lucha por la validación del derecho a la educación de todas las personas sin distinción. Aunado a ello se crea la Unesco y diversas declaraciones de derechos con el fin de impulsar una mayor cobertura y buen funcionamiento de la educación especial. Surge entonces en Iberoamérica un cambio en la educación que deriva en importantes mejoras de impacto social. Coraggio, citado por Díaz, afirma que en este periodo se "caracteriza el surgimiento del nuevo ordenamiento, propuesto por algunos organismos internacionales, entre ellos el Banco Mundial: Se remplaza el paradigma de desarrollo económico por el de desarrollo humano, entendido este último como índice de educación" ${ }^{\prime 40}$. Aunado a ello, en el año 1978 surge el Informe Warnock, documento que afianza el nuevo concepto de necesidades educativas especiales. Mismo que sustituye la visión etiquetante centrada en el déficit que venía liderando los discursos, por un concepto centrado en los apoyos. Este nuevo concepto que sugiere el informe permite que la atención se centre en "lo que el alumno necesita aprender, cómo, en qué momento y con qué recursos" $^{\prime 41}$. A la luz de lo anterior, impulsan las ideas de integración en Latinoamérica iniciando sus manifestaciones.

Así las cosas, surge el segundo elemento principal de esta primera época, que es el de integración. Para que las personas en condición de discapacidad pudiesen disfrutar del mismo sistema educativo y social normalizado se reconoce como imprescindible la integración escolar. Es decir, "el derecho a recibir una educación adecuada a las características individuales del alumno, y deja atrás la división y el etiquetaje"42. Lo anterior en la misma escuela que los demás estudiantes, en un entorno lo menos restrictivo posible, potenciando su interacción social.

En esta línea, Gutiérrez y Urgilés exponen que: "El objetivo del informe de la Unesco de 1968 fue 'definir y delimitar' tanto el concepto como el contexto de la Educación Especial para no entenderlo como déficit o deficiencia, sino orientarlo hacia un desarrollo igualitario en cuanto el ambiente les ofrezca las condiciones y posibilidad para hacerlo" ${ }^{\prime 3}$.

Es así como los esfuerzos se encaminan a reducir las etiquetas y la segregación a la luz del principio de integración. Arnaiz explica que dicho principio "busca un máximo de comunicación y un mínimo de aislamiento de los niños con problemas, facilitando su interacción social" ${ }^{44}$. Según ella, para alcanzar este objetivo "La integración propugna la escolarización conjunta de alumnos normales y con discapacidades y aboga por la inserción de la educación especial en

\footnotetext{
40 Ibíd., 19.

41 Arnaiz, Atención..., op. cit., 17.

42 Ibíd., 14.

43 Cándido Gutiérrez y Guillermo Urgilés, “Historia y perspectivas de la Educación Especial en Latinoamérica”, en Personas con discapacidad y acceso a servicios educativos en Latinoamérica. Análisis de situación, dir. Pilar Samaniego (Madrid: Cermi/Ediciones Cinca, 2009), 121.

44 Arnaiz, Atención..., op. cit., 15.
} 
el marco educativo ordinario, para que se preste la atención adecuada y necesaria a cada alumno según sus diferencias individuales" ${ }^{\prime 4}$.

Más adelante, en los años ochenta, la mayoría de los países latinoamericanos desarrolla acciones en pro de la integración educativa. Podría decirse que los acontecimientos que se suscitaban en España tenían un alto impacto en los cambios consecuentes en Latinoamérica. En este sentido, es importante considerar que "en España, la teoría sobre la integración y su aplicación en el aula se incorpora a partir de 1985 mediante la publicación de un Real Decreto, es decir, se constituye en un texto y obligación legal para el sistema educativo" ${ }^{46}$.

De cara a dicha evolución, en América Latina se lían cambios importantes. Samuel Gento y Ana-María Lamas señalan que en Bolivia, por ejemplo, se muestra una preocupación particular por "la preparación de asesores pedagógicos que puedan impulsar convenientemente la Educación Especial integrada"47. Mientras que en Costa Rica, los servicios educativos segregados en escuelas de educación especial mantenían la atención educativa de la mayor parte de la población en condición de discapacidad.

Gento y Lamas explican que, en este momento histórico, e incluso en la era de los 90, la integración aún no era la alternativa más practicada pese a que se consideraba la oportuna. Los autores exponen que "las justificaciones para ello pueden ser diversas, y van desde las razones de tipo económico (falta de recursos) a las de tipo pedagógico (alumnos con necesidades profundas no pueden ser integrados en situaciones de tipo ordinario)" ${ }^{\prime 4}$. En este sentido, Costa Rica aún mantenía prácticas segregantes en años de perspectivas integradoras.

En Perú, por su parte, según señaló Rojas citado por Gento y Lamas, en el año 1999 este país todavía no contaba con "instituciones que acojan al desarrollo de programas integrados de atención al excepcional" ${ }^{49}$, no obstante, afirman los autores que actualmente "se muestra un interés por avanzar en tal dirección" 50 .

Mel Ainscow, al explicar el desarrollo de la educación especial en países occidentales, afirma que muchos de ellos mantienen de modo paralelo programas segregantes y de integración, lo cual eleva los costos de gasto público. En esta línea, el autor señala que "en algunos países, la integración sólo constituye una aspiración para el futuro" 51 .

Ahora bien, conforme avanzan los años, la educación especial enfrenta varios cuestionamientos, donde la integración, que aún parece no alcanzarse del todo en Latinoamérica, ya es superada por nuevas propuestas. En este sentido, estar integrados implica compartir un espacio físico pero no participar de modo equi-

\footnotetext{
45 Ibíd., 16.

46 Gutiérrez y Urgilés, op. cit., 122.

47 Samuel Gento y Ana-María Lamas, Marco internacional y comparado del tratamiento educativo de la diversidad (Madrid: Universidad Nacional de Educación a Distancia, 2010), 204.

48 Ibíd., 205.

49 Ibíd., 206

50 Ibíd.

51 Mel Ainscow, Desarrollo de escuelas inclusivas. Ideas, propuestas y experiencias para mejorar las instituciones escolares (Madrid: Narcea, S. A. de ediciones, 2004), 244.
} 
tativo; la perspectiva prevalece atendiendo más el déficit que valorizando la diversidad. Al respecto, Arnaiz expone dos razones que se esgrimen de esta postura. Primeramente afirma que, con la integración, "existe un mantenimiento del statu quo que refuerza la idea de que el problema está en el alumno y se obvian otras causas como los procesos sociales, políticos y la propia organización de los centros" ${ }^{\prime 2}$. Por otra parte, la autora señala que la integración perpetúa la etiqueta en la persona, en tanto "sigue justificando la salida/exclusión de las aulas regulares hacia las aulas de apoyo del alumnado con necesidades educativas especiales en muchos momentos del proceso educativo" ${ }^{\prime 53}$. Finalmente Arnaiz justifica, como última razón, que en la integración "el estilo de las respuestas didácticas que caracteriza la planificación educativa centra la atención en los alumnos con dificultades de manera individual, reforzando la idea de que existen tipos de alumnos distintos que requieren maestros diferentes" ${ }^{54}$.

En este sentido, la apología de la integración en pro de la población con discapacidad empezaba a perder fuerza. Gutiérrez y Urgilés señalan que la igualdad "no es un asunto de mimetizarse con el entorno ni tampoco de ocupar un espacio junto a otros, implica ser un elemento activo en el medio y cumplir una función específica dentro del organismo social" ${ }^{\prime 55}$.

Estos pensamientos llevan, en los años 90, al desarrollo de dos eventos importantes que marcan una brecha histórica en la educación especial. El primero fue la conferencia de "Educación para todos" de la Unesco, y la segunda la "Conferencia de Salamanca" en 1994. Ambos eventos defienden la existencia de una educación más equitativa, justa y respetuosa, menos centrada en la sectorización y más en la atención a la diversidad. De ahí emergen nuevas investigaciones como el índice de inclusión, que constituye una "herramienta concreta que ayuda a la escuela a generar una comunidad institucional centrada en la participación y la colaboración para el mejoramiento de la calidad del aprendizaje de cada estudiante sin distinción alguna" ${ }^{56}$. Este documento, según señalan los autores: "Se centra en tres dimensiones: cultura, políticas y prácticas educativas, a partir de las cuales se establecen indicadores asociados e interrogantes cuyas respuestas permiten a la escuela re-pensarse a sí misma para organizar tareas, formular acciones, aplicar sus propuestas y evaluar su proceso de transformación" ${ }^{\prime 27}$.

La inclusión constituye, entonces, la nueva filosofía de pensamiento en el que se enmarca la educación especial. Arnaiz explica que "Una escuela inclusiva ve a todos los alumnos como capaces de aprender y anima y honra todos los tipos de diversidad, como una oportunidad para aprender sobre lo que nos hace hu-

\footnotetext{
52 Arnaiz, Atención..., op. cit., 148.

53 Ibíd.

54 Ibíd.

55 Gutiérrez y Urgilés, op. cit., 121.

56 Ibíd., 123.

57 Ibíd.
} 
manos $^{\prime 58}$. ) En este sentido, la igualdad de oportunidades se vive a la luz del respeto a la diversidad, comprendiendo que la escuela y la sociedad son "un lugar donde todos pertenecen, donde todos son aceptados y son apoyados por sus compañeros y por otros miembros de la comunidad escolar para que tengan sus necesidades educativas satisfechas ${ }^{\prime \prime 5}$. Bajo esta perspectiva, la educación especial constituye una oportunidad para potenciar el respeto a las diferencias, celebrar la diversidad y edificar el aprendizaje sin exclusiones ni eufemismos.

Para este momento histórico, la condición de discapacidad - que en un inicio impulsó el origen de la educación especial- ha perdido importancia significativamente. La etiqueta que en un momento dado la sociedad impuso a la población en dicha condición para decidir sobre su destino, se ha transformado en una responsabilidad ciudadana de abrir espacios accesibles para todas las personas. En esta línea cabe reflexionar sobre la afirmación de Barton citado por Porras, quien señala que "la forma que tiene una sociedad de excluir a los grupos o a los individuos conlleva procesos de categorización en los que se generan y se legitiman las discapacidades y los aspectos inaceptables e inferiores de una persona" ${ }^{\prime 60}$. A la luz de dicha propuesta, se justifican los actos de exclusión responsabilizando a la persona que cuenta con diferencias físicas, psíquicas o sensoriales, mas se libra de compromiso al resto del colectivo.

Hoy por hoy, el concepto de inclusión, más allá de las barreras del aula, ha trascendido a generar impactos políticos en los que ya no existen un "ellos y los otros", sino, por el contrario, un "nosotros", donde que cada quien es igualmente responsable de eliminar barreras, ya sean contextuales o personales, que impidan la participación en igualdad de condiciones para todas las personas.

Aquellas poblaciones que se sectorizaban según sus deficiencias, hoy en día, con los discursos inclusivos, han borrado los límites de la segregación. El concepto de diversidad, que reconoce la condición que todas las personas vivimos, es ahora el estandarte que une las comunidades de aprendizaje y lidera las acciones en beneficio de todos y todas. En este sentido conviene considerar la propuesta de Arnaiz, quien señala que:

La inclusión y el respeto por la diversidad no son principios limitados a los estudiantes con discapacidades o a los estudiantes con altas habilidades; las diferencias culturales, religión, etnia, entorno familiar, nivel económico y capacidad están presentes en todas las clases. En las aulas inclusivas, los compañeros pueden aprender $y$ ayudarse entre sí en todas estas dimensiones con una instrucción eficaz y un apoyo fuerte $e^{61}$.

\footnotetext{
58 Arnaiz, Atención..., op. cit., 62.

59 Ibíd.

60 Ramón Porras, "Marco conceptual", en Personas con discapacidad y acceso a servicios educativos en Latinoamérica. Análisis de situación, dir. Pilar Samaniego (Madrid: Cermi/Ediciones Cinca, 2009), 64.

61 Arnaiz, Atención..., op. cit., 64.
} 
En esta línea, es importante valorar que el nuevo objetivo de la educación especial, más que atender de modo especializado las acciones educativas de una población, se basa en celebrar la diversidad dentro del aula y propiciar espacios de respeto en los que se generen aprendizajes significativos para todo el estudiantado.

Pese a estos alentadores discursos y mejoras en las perspectivas educativas, aún existen en Latinoamérica múltiples centros educativos que propugnan la sectorización, llamados "Escuelas de Educación Especial", que solo atienden la población que comparta la característica de contar con una condición de discapacidad. Frente a esta incuestionable envergadura se hace imprescindible determinar cuáles son las condiciones que atan al estudiantado a dichos entornos excluyentes para así orientar las sinergias a propiciar la educación inclusiva, que garantice sus derechos humanos.

La presente investigación parte de que las barreras de comunicación constituyen una atadura que impide que las personas que asisten a escuelas de enseñanza especial puedan surgir a nuevos escenarios menos segregantes. Por esta razón la muestra seleccionada asiste a dichas escuelas. Cabe aclarar que, en apartados posteriores, se profundizará en la reciprocidad de la comunicación con la inclusión de las personas con discapacidad.

\section{Escuelas de educación especial en Costa Rica}

En Costa Rica, las escuelas de educación especial se han formado de modo gradual y constante, según afirma la investigadora Lady Meléndez: “De 1939 a 2003 han sido creados 25 centros de Educación Especial en el país. Algunos de estos centros atienden a población que presenta alguna forma particular de deficiencia, pero la mayoría atiende a todo tipo de necesidades educativas provocadas por distintas discapacidades, siguiendo la modalidad que mejor se ajuste al estudiante"62.

Dichas instituciones, según Meléndez, reciben al estudiantado desde el nacimiento hasta el cumplimiento de la edad adulta "organizadas según las modalidades de atención directa y apoyo fijo, así como de apoyo itinerante para dar seguimiento a estudiantes incluidos en servicios menos segregados o para brindar atención comunitaria y domiciliaria" ${ }^{\prime 3}$.

Los centros de educación especial del país cuentan con diversos servicios que trabajan de modo interdisciplinario, entre ellos, poseen profesionales en "Trabajo Social, Psicología, Fisioterapia, Terapia del Lenguaje y Terapia Ocupacional entre otros, además de ofrecer asignaturas especiales como Educación Musical, Artes Plásticas, Artes industriales, Educación para la Vida Familiar y Social, Educación Física y otras" ${ }^{\prime 64}$. Estas entidades son reguladas por el Ministerio de

62 Lady Meléndez, La educación especial en Costa Rica. Fundamentos y evolución (San José: Editorial Universidad Estatal a Distancia, 2010), 105.

63 Ibíd., 107.

64 Ibíd., 107-108. 
Educación Pública, y deben responder a los Planes de Estudio de Educación Especial, desarrollados en el Departamento de Educación Especial de dicho ministerio.

Como se ha explicado en apartados anteriores, pasados los años ochenta, tras las investigaciones que sostienen la nueva visión integracionista, Costa Rica se reformula su organización educativa "con la meta de que para los próximos años los servicios segregados sólo seguirán existiendo para aquellos estudiantes cuyo estado de salud o de intensidad y complejidad en los apoyos requeridos lo ameritara" ${ }^{\prime 65}$. Aunado a ello, se decide en esta época que los esfuerzos del profesorado en dichas instituciones se centrarían en "trabajar fuerte y orientadamente para que la estadía del estudiantado fuera lo menos prolongada posible" ${ }^{\prime 66}$. No obstante, las largas listas de espera acumuladas en las instituciones, la recarga laboral del equipo docente y el aumento en la infraestructura de los centros de educación especial costarricenses afirman el hecho contrario: la estadía de la mayor parte del estudiantado, lejos de ser breve, se extiende a lo largo de la vida en contextos educativos segregantes.

En Costa Rica, esta modalidad del servicio educativo "se reserva para la población con mayores necesidades y que está en proceso de preparación para la inclusión educativa" ${ }^{67}$. Por tanto, a este sistema educativo asisten personas que, por su condición de discapacidad, se considera que no podría participar de procesos educativos convencionales. Porras explica que la organización de la educación especial en este sistema sectorizado demuestra que "la aparición de los principios de normalización e integración tampoco impidió, en la práctica, la segregación educativa de las personas con discapacidad"68. El autor describe la atención de los centros de educación especial como "una educación dividida en diferentes vías u opciones según las categorías de los sujetos"69, condición que sin duda perpetúa la exclusión y minimiza las posibilidades de una participación igualitaria en la sociedad.

Es así como el discurso inclusivo pretende trabajar sobre la exclusión más que sobre las personas, es decir, realizar cambios sistémicos que mejoren la calidad educativa que reciben todas las personas en respeto a su diversidad.

No se trata de segregar o negar el derecho a la educación de algunas personas por sus diferencias, pero tampoco se trata de dar una misma y homogénea enseñanza negando las diferencias existentes. Se trata de reconocer las diferencias, valorar a las personas por lo que son y como son, creer en sus posibilidades de mejora y darles la oportunidad de desarrollarse con sus iguales, pues todos somos tan iguales como desiguales y hay que aceptar las semejanzas y las diferencias como algo real e inherente al hecho humano ${ }^{70}$.

\footnotetext{
65 Ibíd., 98.

66 Ibíd.

67 Ibíd., 106.

68 Porras, op. cit., 70.

69 Ibíd.

70 Ibíd., 71.
} 
En tanto este objetivo siga en pie y la educación inclusiva continúe tomando fuerza en Costa Rica, las escuelas de educación especial seguirán en constante evolución. Hoy en día su destino no puede describirse con claridad, la desaparición de las mismas, como se ha dado en Colombia y otros países de Latinoamérica, no es una opción irrevocable. Pero puede afirmarse que hoy, tanto los centros formativos estatales como las entidades regulatorias ministeriales y el Centro de recursos para la educación inclusiva están realizando investigaciones que orientan mejor la toma de decisiones en torno a su destino.

\section{4. ¿Cómo se vislumbra la educación especial en la actualidad costarricense?}

Es necesario recordar que, tanto la integración como la inclusión, constituyen movimientos educativos y sociales en pro de una mejora en la calidad educativa de las personas con necesidades educativas, a la luz de las propuestas de igualdad antes mencionadas.

Según Birch, citado por Marín, la integración educativa es el concepto que antecede a la inclusión, definiéndose como "un proceso que pretende unificar la educación ordinaria y especial con el objetivo de ofrecer un conjunto de servicios a todos los niños, sobre la base de sus necesidades de aprendizaje" ${ }^{\prime 71}$. En este sentido, se protege el derecho de toda persona de asistir a centros educativos convencionales y recibir una educación de calidad. Romero y Lauretti explican que, en América Latina, "la Educación integradora nace de la idea de que la educación es un derecho humano básico y proporciona los cimientos para lograr una sociedad más justa"72. Los autores explican que este objetivo, se justifica:

Educativamente por la necesidad de que se eduquen todos los niños juntos obligando a las escuelas a idear modalidades de enseñanza para las diferencias individuales; socialmente porque al educar a todos los niños juntos se sientan las bases para una sociedad más justa, animando a la gente a vivir junta en paz, y económicamente ya que se ha determinado que el educar a todos los alumnos juntos resulta menos costoso que establecer distintos tipos de escuelas ${ }^{73}$.

España, que sin duda ha encabezado las prácticas educativas que en Costa Rica se reproducen, ha liderado este cambio educativo "descartando a la educación especial como la educación de un determinado grupo de alumnos, dejando en desuso el antiguo modelo médico y psicológico"74.

En Costa Rica, propiamente, explica Marín, "el proceso de integración se inicia en 1973, con las aulas diferenciadas conocidas en la actualidad como aulas integradas. Estas se encontraban ubicadas en escuelas del sistema regular para

71 Gabriela Marín, Alumnos con necesidades educativas especiales (San José: Editorial Universidad Estatal a Distancia, 2008 ), 124.

72 Rosalinda Romero y Paola Lauretti, "Integración educativa de las personas con discapacidad en Latinoamérica”, Revista Educere, 10, n. ${ }^{\circ} 33$ (2006): 348 .

73 Ibíd.

74 Ibíd. 
la atención de niños con retardo mental"75. Dicho sistema persiste hasta la actualidad, no obstante asisten estudiantes que son remitidos de las escuelas de educación especial, con diversas condiciones, desde el nivel de preescolar. Gracias a estos esfuerzos, y las legislaciones que impulsaron, ha aumentado la participación social de personas en condición de discapacidad en esferas laborales, educativas, familiares y comunales con mejores oportunidades.

No obstante, frente a esta incuestionable envergadura, que rompe con la práctica segregante que imperaba en la nación, todavía los principios que la impulsaron, como la búsqueda de una escuela para todos y para todas, no terminan de concretarse. Conviene mencionar que la integración nace como una filosofía que pretendía una mayor igualdad social, como se ha mencionado. Así las cosas, Jorge Correa explica en los años de su auge, que "cuando hablo de integración como filosofía de vida, parto del hecho de que creo en el otro como ser íntegro, tal cual es, en saberes, creencias, potencialidades y necesidades" ${ }^{\prime \prime 6}$. No obstante, al llevar estas propuestas a acciones prácticas en América Latina, y específicamente en Costa Rica, las aulas integradas constituyeron espacios en los que el estudiantado compartía un entorno común pero con diversidad de horarios, espacios académicos y grupos sociales. En este sentido, ahora, en un mismo contexto educativo, prevalecían los actos excluyentes. Lo anterior puede ser explicado con mayor claridad ante la postura de Correa, quien señala que la concepción que se construya sobre la integración "como enfoque es una discusión de orden actitudinal, lo que sí es claro es que dependiendo de la visión que del ser humano tenga el actor social y su experiencia en un mundo cultural, influye la concepción y actitud hacia la integración"77. Es por ello que, en entornos que pudiesen prestarse para una participación igualitaria, las personas que la integran pueden tornar la experiencia en un mero acto de coincidir en momento y lugar sin compartir derechos ni oportunidades.

Al respecto Romero y Lauretti afirman que "por ello se atraviesa actualmente por un cambio ideológico que transforma la integración en la inclusión de las minorías, basados en los principios propuestos por la Unesco"78.

Al tenor de estas apreciaciones, en los años noventa inician, tanto en Costa Rica como en el resto de Iberoamérica, los discursos sobre la educación inclusiva. Ainscow afirma que "en muchos países, la insatisfacción ante los progresos hacia la integración ha provocado la exigencia de cambios radicales" ${ }^{\prime 79}$. Explica que el proceso de integración está cubierto de cuestionamientos que lo inculpan de perpetuar un modelo médico de la educación en el que "las dificultades educativas se explican exclusivamente en relación con los déficit del niño" 80 . En este sentido Ainscow propone que la transformación educativa busque "responder positivamente a la diversidad de los alumnos, considerando las diferencias individuales como oportunidades de enriquecimientos del aprendizaje y no como problemas que arreglar ${ }^{\prime \prime 81}$. Congruente

\footnotetext{
75 Marín, op. cit., 125.

76 Jorge Correa, Integración escolar para población con necesidades especiales (Bogotá: Cooperativa Editorial Magisterio, 2008$), 18$.

77 Ibíd.

78 Romero y Lauretti, op. cit.

79 Ainscow, op. cit., 245.

80 Ibíd.

81 Ibíd., 246.
} 
con estas posturas, Arnaiz afirma que el discurso inclusivo requiere "un desplazamiento hacia una aproximación no-categórica de la discapacidad, que se focalice en las conductas funcionales y en las necesidades de apoyo de las personas, sin tener en cuenta sus diagnósticos clínicos" ${ }^{\prime 82}$. Por esta razón el concepto de inclusión se opone a la educación segregante y trasciende las fronteras de la integración educativa, en tanto que abre la visión de la educación hacia el respeto a la diversidad en todas sus formas, y no únicamente asociada a una condición de discapacidad.

Arnaiz explica que dicho enfoque supone que "en las escuelas inclusivas ningún alumno sale del aula para recibir apoyo, sino que éste se recibe dentro del aula, lo cual exige que los recursos estén en la misma y que los profesores de apoyo realicen una importante tarea de coordinación con el profesor" ${ }^{\prime \prime 3}$. Asimismo, afirma que la educación inclusiva "se centra en construir la interdependencia, el respeto mutuo y la responsabilidad" ${ }^{44}$. En esta línea la educación inclusiva "implica establecer y mantener comunidades escolares que den la bienvenida a la diversidad y que honren las diferencias" ${ }^{\prime \prime 5}$. Sin duda, las alentadoras posturas inclusivas se lían a nuevos desafíos de transformación educativa, ideológica y social. Así las cosas, requieren de cambios que promuevan una participación verdaderamente igualitaria, sin exclusiones ni eufemismos.

Como el resto de Latinoamérica, Costa Rica está en constante transformación en materia educativa. De modo que sus prácticas integradoras y normalizadoras han ido evolucionando paulatinamente hacia un ejercicio más inclusivo de la educación. Pese a ello, coexisten hoy en día prácticas segregantes, integradoras e inclusivas, todas validadas por el mismo Ministerio de Educación Pública. Es así que existen escuelas de educación especial, tal como las participantes del presente estudio, con estudiantes en condición de discapacidad como característica común. Mismas que se centran en clasificar los servicios según las categorías de discapacidad. De igual manera, existen también las aulas integradas a las que solo asisten estudiantes que comparten diagnósticos asociados a una discapacidad, pero inmersas en escuelas regulares. No obstante, el estudiantado que no cuenta con ninguna condición de discapacidad, y aquellos que asisten al aula integrada, no comparten espacios sociales ni académicos en su mayoría. Por último están los servicios de apoyo que se respaldan en principios inclusivos pero que ahora están organizados para trabajar con la población que presente necesidades educativas, relacionadas a dificultades de aprendizaje y no a otra condición de diversidad.

Puede decirse entonces que el proceso hacia la inclusión ha implicado altos niveles de resistencia, sobre todo de aquellas personas que laboran y asisten a los centros de educación especial. Estos contextos suponen espacios donde el estudiantado debe adaptarse a las ofertas del sistema, en el cual se considera que el derecho a la educación es una concesión. No obstante, la segmentación de la población estudiantil se realiza por niveles y por condición de discapacidad, es decir, que orientan su atención educativa por su diagnóstico clínico antes que por su personalidad, capacidad u otras características personales. Es por ello que los ambientes de un centro de

\footnotetext{
82 Arnaiz, Atención..., op. cit., 55.

83 Ibíd., 56.

84 Ibíd.

85 Ibíd., 63.
} 
educación especial, que dice ser integrador, se basan en organizaciones segregantes y poco igualitarias. Al respecto, Meléndez define dicha atención como educación segregada, es decir, una "modalidad de enseñanza que reúne a los alumnos en razón de su discapacidad para aplicarles un plan de estudio especial, en un espacio físico separado del que comparten sus coetáneos sin discapacidad"86. En estos contextos "los educandos sólo comparten con pares en similares condiciones y con sus maestros y profesionales de apoyo" ${ }^{\prime 87}$.

Ahora bien, si a estas condiciones excluyentes se le suma que muchas de las personas asistentes a dicha institución no cuentan con recursos comunicativos funcionales, su limitada posibilidad de interacción y socialización es aún más confinada. En este sentido Scheeremberger, mencionado por Meléndez, critica que en el aislamiento de la educación segregada "se les niega la oportunidad de mezclarse con los otros chicos de su edad y se les priva así de una experiencia social que podría estimular su desarrollo"88; el autor agrega que, gracias a dicho sistema, "se pierde la sensación de seguridad que se deriva de la conciencia de pertenencia a un grupo"89.

Pese a que todas las críticas a la educación segregante iniciaron en los años setenta producto del surgimiento del integracionismo, aún hoy, más de cuatro décadas después, se siguen justificando estos ambientes, en su mayoría destinados a la atención de la población estudiantil en condición de discapacidad severa. No obstante, algunos autores como Meléndez se preguntan si esta separación responde a los apoyos que puede recibir la población con discapacidad en estos ambientes, "qué pasaría si se decide mejor desconcentrar estos apoyos y enviarlos coordinada y organizadamente hasta donde se encuentran los alumnos integrados" ${ }^{\prime \prime 0}$, de modo que si la preocupación recae en los servicios y no en la persona, entonces, Meléndez propone "modificar las formas de atención, de tal manera que este no se prive de los beneficios de un ambiente integrador" ${ }^{\prime \prime 1}$.

En esta línea conviene analizar la propuesta de Rosa Blanco en torno a que la educación especial ha trabajado más en su transformación para mejorar la integración, de modo que persigue "cambiar la cultura y práctica de las escuelas comunes para que sean capaces de atender la diversidad del alumnado, y eliminar los diferentes tipos de discriminación que tienen lugar en el interior de ellas"..$^{92}$ Es decir, la integración se ha concentrado más en la atención específica de las necesidades de cada estudiante "que de modificar aquellos factores del contexto educativo y de la enseñanza que limitan la participación y el aprendizaje no sólo de los niños y jóvenes integrados, sino de todo el alumnado". ${ }^{93}$ De este modo se obvian las condiciones contextuales que interfieren significativamente, tanto en el aprendizaje como en el desarrollo integral del estudiante y del colectivo en el que está inmerso.

\footnotetext{
86 Meléndez, op. cit., 55.

87 Ibíd.

88 Ibíd., 55-56.

89 Ibíd., 56.

90 Ibíd.

91 Ibíd.

92 Rosa Blanco, "La equidad y la inclusión social: uno de los desafíos de la educación y la escuela hoy", Revista Electrónica Iberoamericana sobre Calidad, Eficacia y Cambio en Educación (REICE), 4., n. ${ }^{\circ}$ (2006): 5.

93 Ibíd.
} 
Frente a la situación tan discrepante que enfrenta la nación - considerando una filosofía inclusiva en sus discursos pedagógicos, en contraposición con los servicios educativos que ofrece-, es común enfrentarse con una vasta gama de estudiantes que reciben tratos excluyentes asociados a una condición de discapacidad. Sirva como ejemplo la organización departamental de los centros de educación especial en los que se clasifican los grupos bajo el nombre de "servicio de discapacidad múltiple", "servicio de discapacidad intelectual" y "servicio de trastornos emocionales", haciendo alusión al diagnóstico clínico por encima de cualquier otra característica personal.

Se hace urgente recordar los principios de la pedagogía moderna responden a la "potencialidad humana, su grado de desarrollo y la proporcionalidad en el tipo de trabajo intelectual que se establece en la escuela" ${ }^{94}$; debe entonces pensarse "bajo un principio indulgente, amoroso y flexible en el mismo acto educativo" ${ }^{\prime \prime 5}$, construyéndose sobre las capacidades, promoviendo una mirada altruista y separando las clasificaciones retóricas y poco eficientes del estudiantado, que generan desigualdades desde las prácticas educativas.

En Costa Rica, las buenas prácticas de la educación inclusiva deben divulgarse y los espacios de discusión en esta temática deben proliferarse en virtud de ofrecer una educación de calidad para todo el estudiantado. La educación especial, por su parte, debe renunciar a ser "especial", es decir, dejar de centrarse en las personas que el sistema excluye, para convertirse en educación inclusiva, gestora de igualdad en los espacios educativos y promotora de cambios sistémicos para eliminar la exclusión educativa.

\section{CONCLUSIÓN}

Este artículo platea una coyuntura acerca de la transformación que transita la educación especial en Costa Rica. En este sentido, se reconoce la convergencia de prácticas educativas segregantes, integradoras e inclusivas bajo un mismo sistema educativo.

Los modelos que han evolucionado históricamente en la construcción del concepto de discapacidad, obligan a la ciudadanía a abrir espacios de diálogo y de mayor participación para esta población, en el marco del respeto, la igualdad y la validación de sus diferencias. Lo anterior exige a la educación especial gestar espacios inclusivos más allá de los ambientes escolares.

Los discursos sobre inclusión han puesto en jaque la epistemología de la educación especial y su trascendencia en los demás ámbitos educacionales. Si toda la población estudiantil debe y merece estar en un mismo contexto educativo, ¿Cuál es la cabida de un proceso de educación paralelo al convencional? ¿A quiénes debe atender un docente de educación especial en un entorno inclusivo?

94 Absalón Jiménez Becerra, "Pensamiento pedagógico colombiano: Martín Restrepo Mejía. Una mirada a sus conceptos de pedagogía, infancia, maestro y escuela”, Revista Historia de la Educación Latinoamericana, 19, n. 29 (2017): 245-69. https://doi. org/10.19053/01227238.7578.

95 Ibíd. 
La educación especial, en este replanteamiento, se orienta hacia la gestión de espacios inclusivos, la promoción de entornos cooperativos y la validación de las diferencias individuales en los espacios escolares. Para lograrlo, debe desarrollarse en los entornos menos restrictivos posibles, esto es, en las mismas aulas escolares a las que asiste todo el estudiantado, tenga o no, una condición de vulnerabilidad.

Como se ha detallado, tanto América Latina, como Costa Rica, transitan por un proceso de transformación, abanderados con las posturas sobre la igualdad de participación en todos los espacios sociales. En este paso, el conflicto ha estado presente en los debates educativos, las reflexiones sobre la epistemología de la educación especial y los replanteamientos sobre viejas prácticas se han puesto en cuestión.

No obstante, persisten entornos segregantes, o incluso estudiantes en un mismo sistema educativo pero viviendo excluidos de la participación en igualdad. Esto indica que los cambios aún requieren de mayores oportunidades de diálogo y reflexión, a este respecto, es imprescindible que los entornos educativos reconozcan la discapacidad desde el modelo social con la responsabilidad que esto implica en la ruptura de barreras para la participación.

La inclusión social, por tanto, debe nacer del seno de la cultura, estar inmersa en la comprensión de mundo y las convicciones de cada ciudadano. De otro modo, las normas, leyes y reglamentos que imponen la igualdad de oportunidades, no serán más que un mero discurso sin trascendencia significativa. El cambio debe hacerse desde adentro, puede decirse entones, que la educación misma es la herramienta liberadora que romperá con estas brechas de desigualdad, siempre que haga uso de la criticidad en el interior de cada ciudadano o ciudadana. Si la educación especial aspira a la igualdad, debe entonces preocuparse porque todas las personas implicadas en el proceso, compartan esa misma aspiración.

\section{REFERENCIAS}

Amate, Alicia y Armando Vásquez, eds. Discapacidad: lo que todos debemos saber. Washington, D. C: Organización Panamericana de la Salud, 2006.

Ainscow, Mel. Desarrollo de escuelas inclusivas. Ideas, propuestas y experiencias para mejorar las instituciones escolares. Madrid: Narcea, S.A. de ediciones, 2004.

Arnaiz, Pilar. Educación inclusiva: una escuela para todos. Málaga: Ediciones Aljibe, S.L, 2003.

Arnaiz, Pilar. Atención a la diversidad. Programación curricular. San José: Editorial Universidad Estatal a Distancia, 2013.

Asamblea Legislativa, "Ley 7600. Igualdad de oportunidades para las personas con discapacidad" (San José: Ministerio de Justicia, 1996).

Blanco, Rosa. "La equidad y la inclusión social: uno de los desafíos de la educación y la escuela hoy". Revista Electrónica Iberoamericana sobre Calidad, Eficacia y Cambio en Educación (REICE), 4, n. ${ }^{\circ} 3$ (2006): 1-15.

Correa, Jorge. Integración escolar para población con necesidades especiales. Bogotá: Cooperativa Editorial Magisterio, 2008.

Díaz, Olga. "Conceptualización de la educación especial en Iberoamérica”. En La educación especial en Iberoamérica, editado por Olga Díaz, Sandra Rojas y Eloísa Vasco, 9-34. Madrid: Organización de Estados Iberoamericanos (OEI), 2000.

Gallego, José Luis y Antonio Rodríguez. Bases teóricas y de investigación en educación especial. Madrid: Ediciones Pirámide, 2012.

Gento Palacios, Samuel y Ana María Lamas. Marco internacional y comparado del tratamiento educativo 
de la diversidad. Madrid: Universidad Nacional de Educación a Distancia, 2010.

Gordillo, Enrique. "Historia de la educación mixta y su difusión en la educación formal occidental". Revista Historia de la Educación Latinoamericana, 17, n. ${ }^{\circ}$ 25, (2015): 107-24. https://doi. org/10.19053/01227238.3814.

Gutiérrez, Cándido y Guillermo Urgilés. “Historia y perspectivas de la Educación Especial en Latinoamérica". En Personas con discapacidad y acceso a servicios educativos en Latinoamérica. Análisis de situación, dirección de Pilar Samaniego, 115-170. Madrid: CERmi/Ediciones Cinca, 2009.

Jiménez Becerra, Absalón. “Pensamiento pedagógico colombiano: Martín Restrepo Mejía. Una mirada a sus conceptos de pedagogía, infancia, maestro y escuela". Revista Historia de la Educación Latinoamericana, 19, n. ${ }^{\circ} 29$ (2017): 245-69.

Marín, Gabriela. Alumnos con necesidades educativas especiales. San José: Editorial Universidad Estatal a Distancia, 2008.

Meléndez, Lady. La educación especial en Costa Rica. Fundamentos y evolución. San José: Editorial Universidad Estatal a Distancia, 2010.

Naciones Unidas. Convención sobre los "Derechos de las Personas con Discapacidad y Protocolo Facultativo". New York: Naciones Unidas, 2006. Acceso el 16 de mayo de 2015. http://www. un.org/disabilities/documents/convention/convoptprot-s.pdf

Organización Mundial de la Salud y Organización Panamericana de la Salud. Clasificación Internacional del Funcionamiento, de la Discapacidad y de la Salud. Madrid: Instituto de Mayores y Servicios Sociales (IMSERso), 2001. Acceso el 20 de julio de 2016. http://apps.who.int/iris/ bitstream/10665/43360/1/9241545445_spa.pdf

Palacios, Agustina. El modelo social de discapacidad: orígenes, caracterización y plasmación en la Convención Internacional sobre los Derechos de las Personas con Discapacidad. Madrid: CERMi/Ediciones Cinca, 2008.

Porras, Ramón. "Marco conceptual". En Personas con discapacidad y acceso a servicios educativos en Latinoamérica. Análisis de situación, dirección de Pilar Samaniego, 27-71. Madrid: cermi/Ediciones Cinca, 2009.

Romero, Rosalinda y Paola Lauretti. "Integración Educativa de las personas con discapacidad en Latinoamérica". Revista Educere, 10, n. ${ }^{\circ} 33$ (2006): 347-356.

Unicef. Estado mundial de la infancia. Niñas y niños con discapacidad. Nueva York: Unicef, 2013. Acceso el 4 de julio de 2016. http://www.unicef.org/spanish/sowc2013/files/SPANISH_SOWC2013_ Lo_res.pdf.

Como citar:

Deliyore Vega, María del Rocío. “Costa Rica, de la educación especial a la educación inclusiva. Una mirada histórica" Revista Historia de la Educación Latinoamericana. Vol. 20 No. 31 (2018): 165-187 DOI: $10.19053 / 01227238.8600$ 


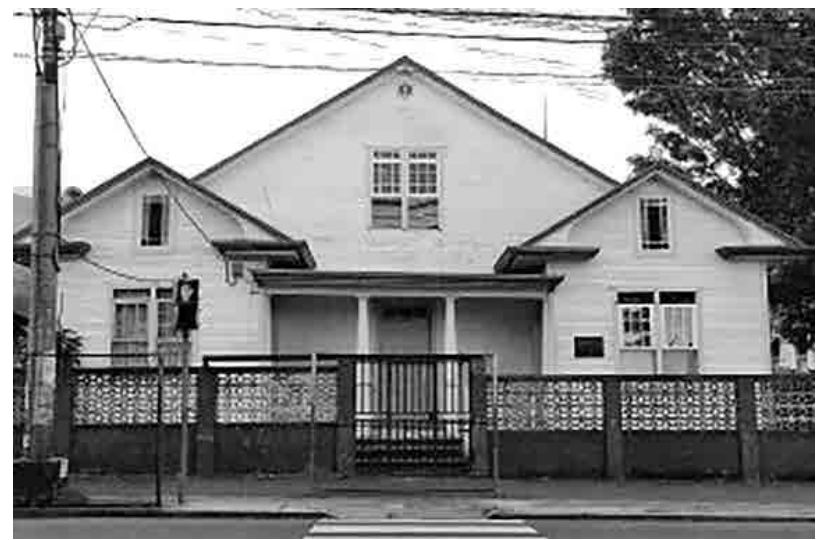

Fuente: Primera Escuela para personas con discapacidad en Costa Rica, inaugurada en 1940, llamada Fernando Centeno Guell en honor a su fundador. Fotografía tomada por: Mario Rojas (2008), para el Periódico La Nación, San José, Costa Rica. 